\title{
Teaching Sustainability in Design without Greenwashing
}

\author{
Ulrike Heine \\ School of Architecture, Clemson University, Clemson SC 29634-0503, USA
}

\begin{abstract}
Teaching design incorporating a sense of sustainability to architecture students is a challenge today, primarily because of the trend to label every design as sustainable or green even though it is no different from a more traditional one. The result is a "green-washed" education in architecture. To address this issue, this paper describes a teaching methodology of architectural design with a special focus on sustainability implemented in the Graduate School of Architecture in Clemson. This method includes an analysis of the location, the climate conditions, the materials needed and the construction process. Knowing that sustainable design is generally perceived as being expensive, there is a special focus on simplicity and affordability. Rather than relying on expensive technical solutions, students are encouraged to design for the given environment and apply passive strategies. In the approach discussed in this paper, the design process is a number of logical scientific decisions rather than an intuitive draft. The goal of this pedagogy is to raise awareness about how to handle global resources carefully and to show the importance of the later performance of the project as a key to design. The teaching strategy is described here along with the successful participation by our graduate students in a number of refereed competitions.
\end{abstract}

Key words: Sustainability, design, teaching, passive design strategies, energy efficiency, affordability.

\section{Introduction}

All basic needs for human survival come from the natural environment-light, water, air, food, minerals and materials. Sustainability is a frame of mind in which we see ourselves as part of this environment, not as consumers of it, and, therefore, conservers of these resources not only for ourselves but also for future generations. The current anthropocentric view of the planet is one in which we have the right to exploit "our" land as we see fit, regardless of the larger consequences to other organisms or the complex cycles regulating the environment. In contrast, the sustainable concept is one in which we see ourselves as part of a larger whole, one without which we cannot survive. Sustainability is an approach which emphasizes stewardship, not ownership, which makes us aware of and responsible for every action we take, and

Corresponding author: Ulrike Heine, assistant professor, research fields: sustainable housing and affordable sustainability. E-mail: ulheine@clemson.edu. which attempts to create and maintain the conditions under which humans and nature can coexist in productive harmony.

Applied to architecture, sustainability is the managing of resources in order for a building to operate efficiently and function based on an environmentally sensible design. The primary strategies for achieving this goal is through the use of local renewable, durable materials and passive and active systems. Local and renewable materials reduce energy use in transportation and manufacturing, and the durability of these materials extends their life spans while at the same time reducing the maintenance required. Passive systems reduce the amount of energy required by using energy-neutral architectural devices and systems, and active systems take this a step farther by resulting in negative energy use, bringing the energy performance below zero mark. 


\section{Integrated Design or Greenwashing?}

Integrated design, a comprehensive method emphasizing the development of a holistic design, evolved, in part, because of the current focus on sustainability. In contrast, conventional building design usually considers the spatial design first and then the technical aspects such as structure, mechanical systems and energy reducing strategies. This design method does not involve all of the necessary technical fields in the planning and design process, and therefore does not take into account their needs. As a result, in some instances, incompatible elements of the design are not discovered until late in the process when it is "against the concept" to make changes. Integrated design, on the other hand, requires multidisciplinary thinking as it involves a "whole building design" approach. It views a building as an interdependent system as opposed to an accumulation of separate components (site, structure, systems and use). The goal of considering all the systems together is to ensure that they work in harmony rather than against one another. This approach appeals to architects since their discipline requires a broad knowledge of related disciplines such as structures and mechanical systems, meaning that the product of architectural design is a result of logical and scientific decisions rather than a piece of spatial art.

However, rather than incorporating integrated design into sustainable architecture, what resulted was greenwashing, the opposite of both concepts. The term greenwashing, coined by New York environmentalist Jay Westerveltin in 1986, is generally used when significantly more money or time is spent advertising being green, i.e., operating in consideration for the environment, rather than spending resources on environmentally sound practices. This practice often changes the name or label of a product or a piece of a design to evoke the natural environment or nature, for example putting a green roof on a home at the very end of the design process.

\section{Case Study/Dow Solar Design to Zero Competition 2011}

\subsection{Background}

To address some of the world's most pressing environmental issues, Dow Chemical Company sponsored a competition in 2011 on innovation and sustainable solutions. Contestants were asked to develop and propose novel ideas for achieving affordable, high-performing, energy-efficient housing solutions on a global scale. This competition was open to all undergraduate or graduate students worldwide studying design, interior design, sustainable design and other relevant subjects. It was envisioned as a global brainstorming exercise in which competitors would cooperate in an ongoing dialogue and assessment of ideas. The competition was peer-reviewed in three elections: (1) schematic design; (2) design development; (3) final design.

Clemson University participated with seven graduate student teams advised by assistant professor Ulrike Heine (design + sustainability) aided by associate professor Dan Harding (community design + built) and Bernhard Sill (design + structures). Of these seven, six teams were named finalists and five earned awards, including a first and a second prize. The submittal was a website.

\subsection{Research}

As a first step, students were requested to chose a site for their project and to research the local conditions in detail, including the zoning of the site, the local transportation and the surrounding architecture in addition to the local building materials and construction methods. A special focus was to be local historic architecture from the time before the invention of air conditioning.

The second stage of the research focused on the specific climate of the location, the maximum and minimum temperatures for the year, the seasons and the day, the wind speed and directions, the humidity levels and the amount of precipitation throughout the 
year. The research also included the evaluation of the initial suggestions for materials, the orientation of the building, the active strategies for energy conservation and the passive strategies, like orientation, for improved general performance.

The third component of the research was conducted on the specific building typology of the design task - in this case residential buildings - the definition, the internal organization, the optimized measurements according to Ernst Neufert, and the codes required. Case studies from all around the world were analyzed for their cultural differences and to question the students' personal experiences.
The following graphics are the exemplary submittance of one of the award winning projects.

The project is located in downtown Greenville, South Carolina (Figs. 1a and 1b), the second largest city in the state with a metropolitan area population of 636,986 . The site is in walking proximity to important cultural centers, parks, restaurants, schools, amenities and businesses. Site conditions include a slope of approximately $13.2 \%$ along the east-west axis, existing hardwood trees, a clinic building to the north, residences to the east and south, and a public park to the west.

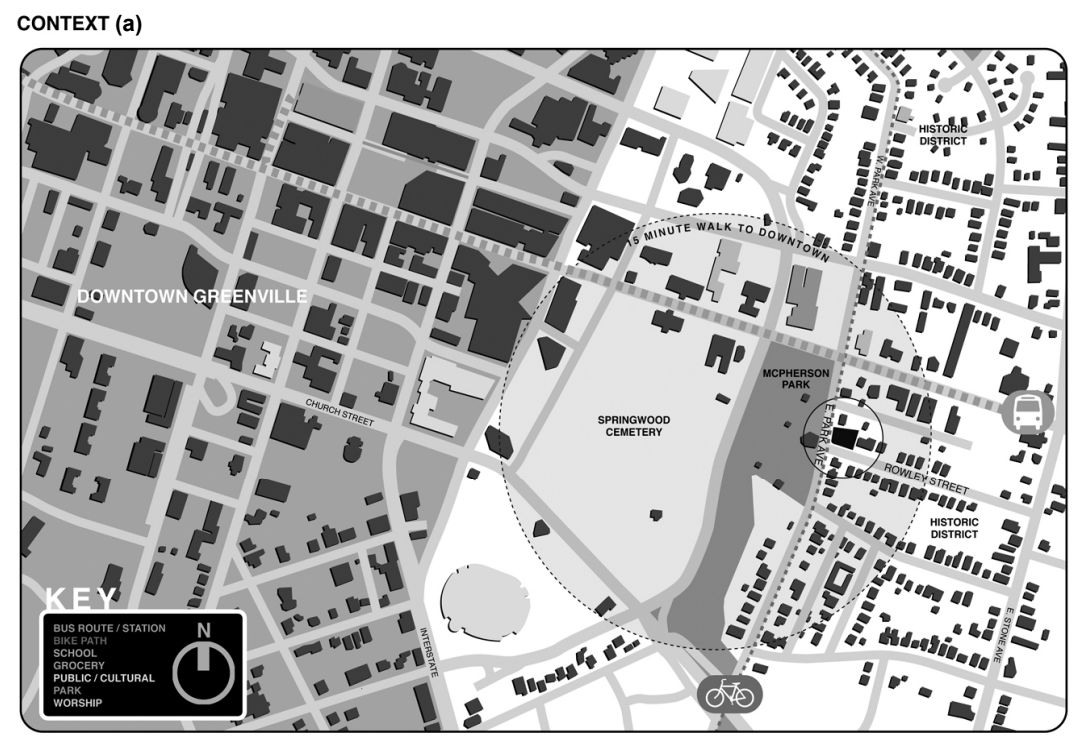

CLIMATIC CONTEXT (b)

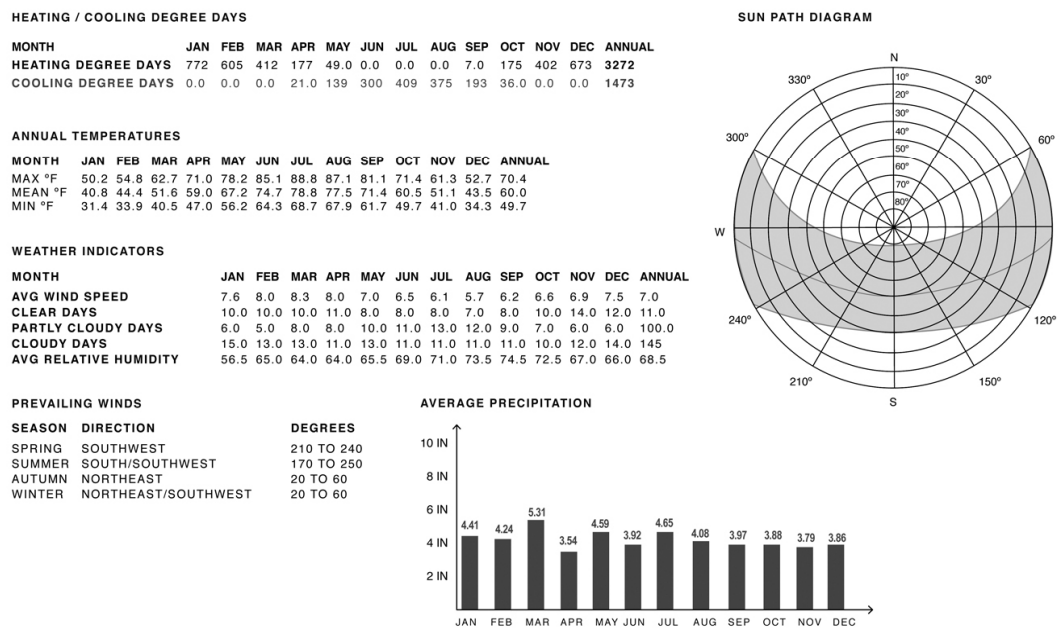

Fig. 1 Design to zero competition [1]: (a) site context; (b) climate analysis. 


\subsection{Programming}

One task of the competition was the definition of a program of a 2, 4 and 6 person household. According to census data, the size of American housing dramatically increased from 1950 until 2008, when it decreased by $1.6 \%$ as a reaction to increasing energy costs. Since then a minimal, but continuous decrease in the size of the average residential home has been observed.

Challenged with the task of creating a vision for the home of the future, the students were requested to recalculate the spatial needs of a family, keeping in mind that every cubic feet of space was to be supplied with energy provided by their own energy-gaining devices.

After an analysis of which spaces are occupied during the day and night and how they can be optimized, the teams reduced the average house size by $25 \%-40 \%$, combining the social spaces like the living, kitchen and dining areas to create one spacious area while reducing the bedrooms and bathrooms to functional units (Table 1).

\subsection{Design Concept}

All of these design concepts were then placed in urban and spatially defined conditions, with a special emphasis placed on implementing the design in response to given contexts and building lines. As a

Table 1 U.S. Census Bureau, median and average square feet of floor area in new one family houses sold by location, 2008 [2].

\begin{tabular}{lcl}
\hline Year & Avrage $\mathrm{ft}^{2} /$ Household & Increasing size in \% \\
\hline 1950 & 983 & $100 \%$ \\
1980 & 170 & $172 \%$ \\
1985 & 170 & $179 \%$ \\
1990 & 250 & $208 \%$ \\
1995 & 2,050 & $208 \%$ \\
2000 & 2,265 & $230 \%$ \\
2005 & 2,414 & $245 \%$ \\
2006 & 2,456 & $249 \%$ \\
2007 & 2,479 & $252 \%$ \\
2008 & 2,438 & $248 \%$ \\
\hline
\end{tabular}

basic strategy, it is expected that environmentally friendly buildings need to be linked to sustainable urban strategies in order to avoid further spread of surburbia with its negative impacts of commuting, unnecessary land consumption and the degrading of the population [3]. The background research on the local conditions and climates shaped the buildings in terms of their geometry, orientation and size (Fig. 1a).

\section{Passive Design Strategies}

Their research provided the students with tools and information to shape their concepts through passive strategies, the idea being to achieve improved performance before thinking about energy gaining strategies. Simulations on design builder showed that the performance of a design incorporating such passive strategies is already $30 \%$ more efficient than a standard design. The following strategies were implemented in the students' designs, although not all of them were brought into every concept.

\subsection{Compactness (Building Form and Building Proportions)}

The compactness of a building, which measures the surface area $(S)$ per volume unit $(V)$ (compactness $=$ $S(V)$, is related to the heat exchange between the building and the ambient environment and, therefore, according to the thermo-physical characteristics of its materials defines the ability to store and release heat. The ratio of volume to surface is an indication of the rate at which a building heats up during the day and cools down during the night. In any project, the urban design is defined by the parameters of distance between buildings (density), orientation, access, parking and open spaces, all of which influence later energy use.

The building form and its compactness are relevant to the amount of heat loss, which is proportional to the insulating quality and to the heat transmitting surface. The most compact shape for a freestanding house is a cube. The design of an individual house should be 
considered with regard to compactness, natural lighting and solar heat gain.

The project redefines the living unit by decreasing the size, cost and energy footprint without diminishing design or sacrificing detail. The building maintains a level of simplicity through form, particularly in plan, but affords spatial complexity through experience, particularly in section, where forms interlock and layer to generate zones, increase ventilation and provide overhangs and adjacencies. The design incorporates planned ambiguity that blurs the boundary between interior and exterior spaces (Fig. 2), creates moments of pause and framed views, and plays with light for both aesthetic and environmental purposes. The units are all tied together by the central underground shared mechanical room, accessible through the parking area, where water and energy are stored and distributed.

\subsection{Orientation}

The orientation of a building must be considered in relation to the sun and prevailing winds. Unfortunately, in most situations they are not compatible and, as a result, compromises must be made. The solar orientation determines the intensity of the solar radiation, therefore, the following rules need to be considered: The greatest intensity of solar radiation occurs on horizontal surfaces; The greatest intensity of solar radiation on vertical surfaces is on the eastern (morning) and western (afternoon) façades; The southeastern surface is subjected to less radiation during the hot season (high temperature) and more during cold seasons (low temperatures); The radiation increases in northerly latitudes. To determine the equilibrium between the welcome solar gain in winter and protect against the undesired solar gain in summer,

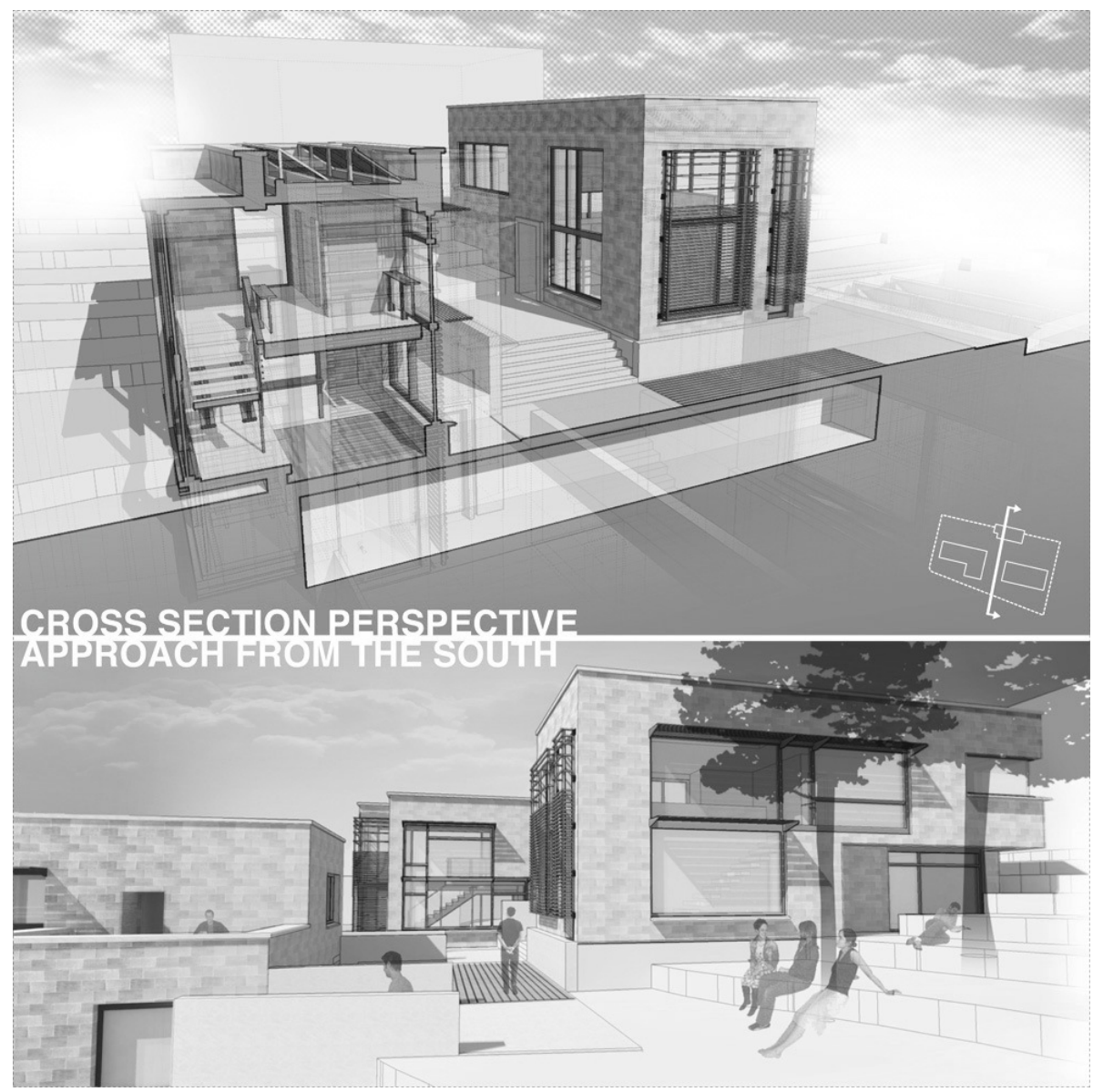

Fig. 2 Design to zero competition, spatial concept [1]. 
shading devices, operable and permanently installed, need to be implemented into the design. The wind orientation should be considered to maximize the natural ventilation. The greatest pressure on the windward side of a building is obtained when it is perpendicular to the direction of the wind, but even openings at a 45-degree angle to the prevailing wind direction increases the air velocity and improves the natural ventilation within the building [4]. Each building has to be studied holistically, taking into account all aspects of the bioclimatic design.

While working on their projects, the students were encouraged to simulate their designs in such programs as Ecotect or Sketchup to determine the optimal orientation and exposure to the sun.

\subsection{Passive Ventilation}

Ventilation should allow fresh air from the outside to flow through the building to facilitate, for example, evaporative cooling of the air, the occupants and the structures. Normally the openings for air movement correspond poorly with the ones for natural lighting, therefore, they should be treated separately. In general, there are two kinds of natural ventilation:

- through wind-generated pressure differences (i.e. different sizes of openings);

- through temperature-generated pressure, differences (natural lifting forces).

If the specific climate of the project provides a sufficient difference in temperature between day and night, night cooling should be considered as an efficient method of passive cooling. In this situation, the building should be closed during the day to avoid an overheating of the spaces and be opened during the night [5].

The complex is oriented along the east-west axis to maximize solar gain and take advantage of existing wind patterns (Fig. 3).

\subsection{Passive Solar Design}

Passive solar design refers to the use of the sun's energy for the heating and cooling of inhabited spaces. Using this approach, the building itself, or some element of it, takes advantage of the natural energy characteristics in the materials and the air created by exposure to the sun. Passive systems are simple, have few moving parts, require no mechanical systems and involve minimal maintenance.

Operable windows, thermal mass and thermal chimneys are common elements found in passive design. Operable windows, which are windows that can be opened, should be oriented properly and their size optimized. Thermal mass, which refers to materials such as masonry and water that can store heat energy for an extended time, prevents rapid temperature fluctuations. Thermal chimneys create or reinforce the effect of hot air rising to induce air movement for cooling purposes.

\subsection{Passive Cooling}

Cooling is linked to the concepts of ventilation. If the temperature inside is higher than outside, the heat

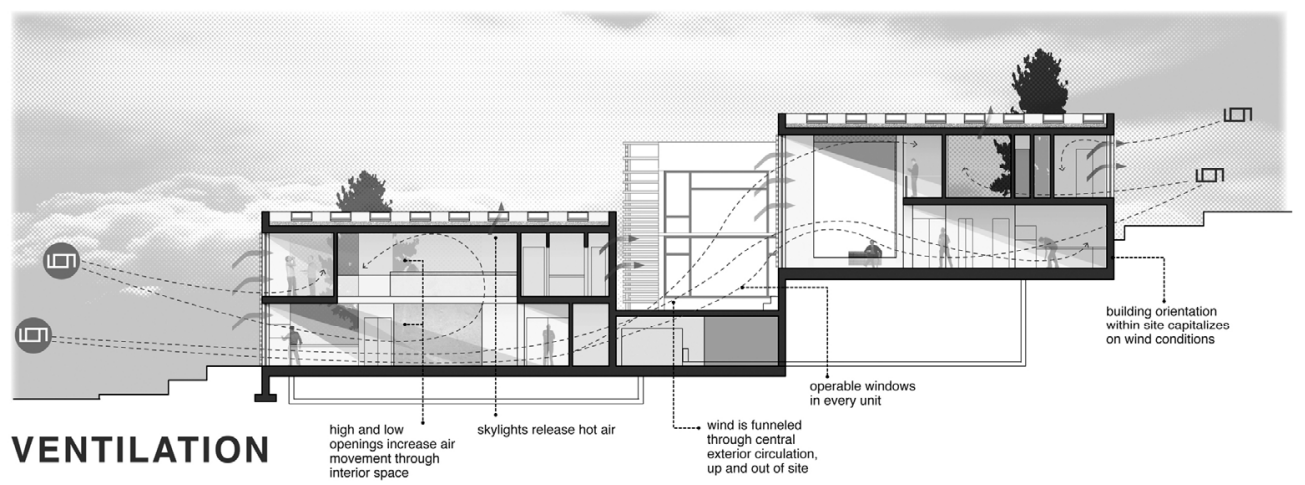

Fig. 3 Design to zero competition, ventilation concept [1]. 
can be removed through natural or mechanical ventilation. Cross ventilation forced by openings on two sides of the space optimizes natural heat extraction. Convective ventilation, usually realized in spaces with high ceilings, takes advantage of the natural lifting forces and replaces the rising warm air with fresh air. The higher the space, the higher the air change rate. Heavy, massive elements can provide thermal capacity for the absorption of internal heating loads and the temperature fluctuation in a space. This approach, referred to as Building Component Activation, takes advantage of this and warms or cools such solid building components as walls or ceilings through active (water) or passive (ventilation) measures.

\subsection{Natural Lighting}

The goal of planning the lighting is to achieve maximum daylight autonomy through the optimization of the building. The openings need to be designed to provide an optimal amount of light in the house while at the same time being adjustable to create an appropriate shading device when needed. At times, natural light is not feasible or even undesirable, in these situations, an adequate source of artificial light needs to be provided, one that fits the needs but uses as little energy as possible. Numerous computer programs can be used to simulate the light situation in a building. Topics like color distortion, freedom of glare and good contrast should be considered $[5,6]$.
The redefined unit maximizes natural daylight while also affording the users a high level of control over their environment. Each space within each unit is penetrated by natural light during the day. Interior spaces expand their minimal footprint by opening onto exterior living spaces and taking advantage of the moderate climate (Fig. 4).

\section{Active Design Strategies}

The following active design strategies were brought to the students' attention in a separate seminar covering building technology and technical resolution. All students were required to take this class in addition to the studio. Every strategy was analyzed based on their applicability to the specific climate zone and local conditions.

\subsection{Photovoltaic}

Photovoltaic panels produce electrical power on site by converting solar radiation into direct current electricity, either as a stand-alone or a grid-connected system $[5,7]$. The students were challenged to orient and tilt them optimally and integrate them into their designs. They were requested to estimate and calculate the energy needs of the households and size the systems accordingly (Fig. 5).

The optimal way to save embedded energy and money is to make buildings last longer. The redefined unit uses durable, local, sustainable and beautiful materials. Smart active systems are installed, and are

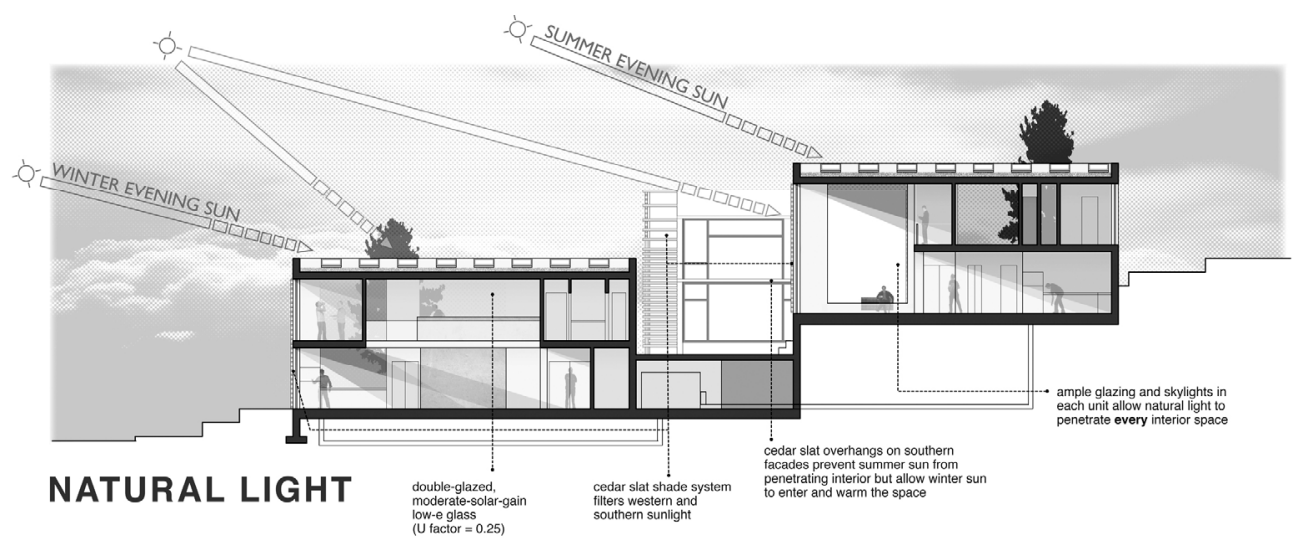

Fig. 4 Design to zero competition, light concept [1]. 


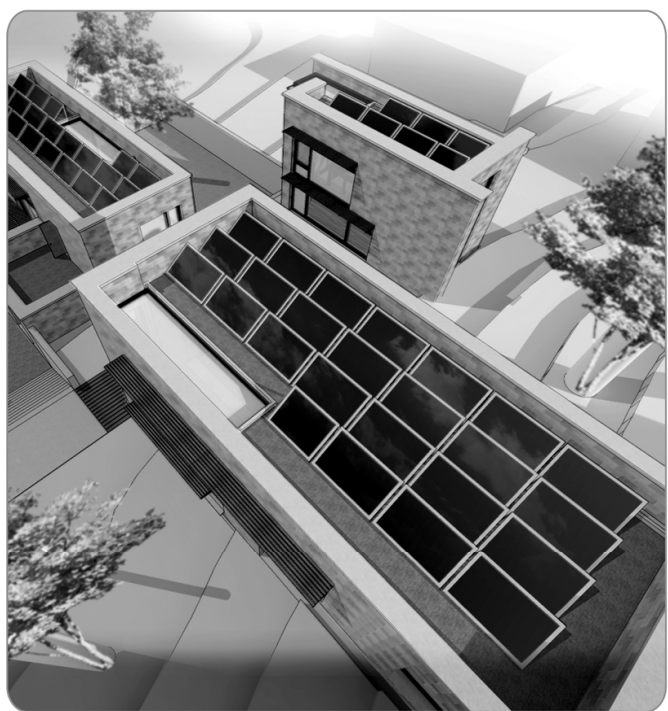

CALCULATING SOLAR THERMAL PANELS

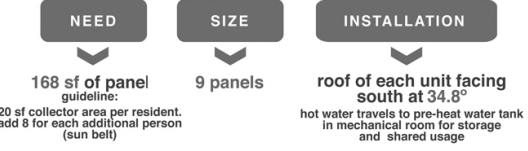

GREEN ROOF ON 6-PERSON UNIT

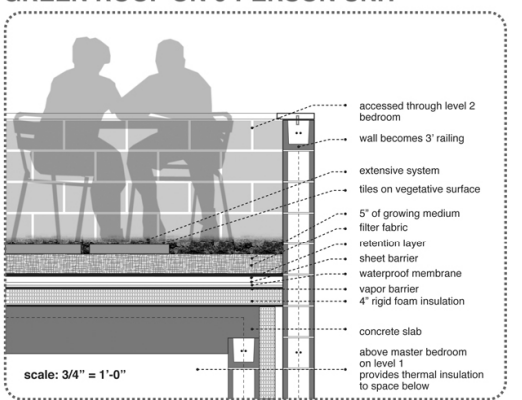

CALCULATING 100\% ENERGY WITH PV PANELS

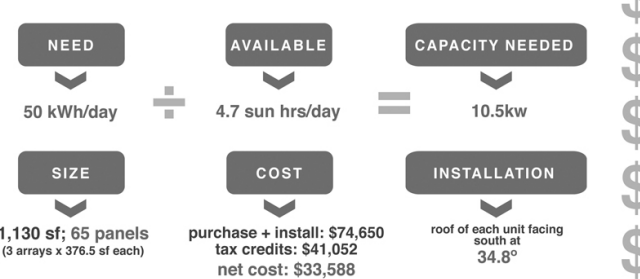

SAVINGS + BENEFITS

Based on 25-year expected life of system.

APPRECIATION IN PROPERTY VALUE

RETURN ON INVESTMENT

GREENHOUSE GAS SAVED (CO)

25-YEAR UTILITY SAVINGS

$133 \%$

AVERAGE ANNUAL UTILITY SAVINGS

246 TONS

BREAK EVEN POINT (recouped initial cost) 11 YEARS

Fig. 5 Design to zero competition, roof system—energy and hot water [1].
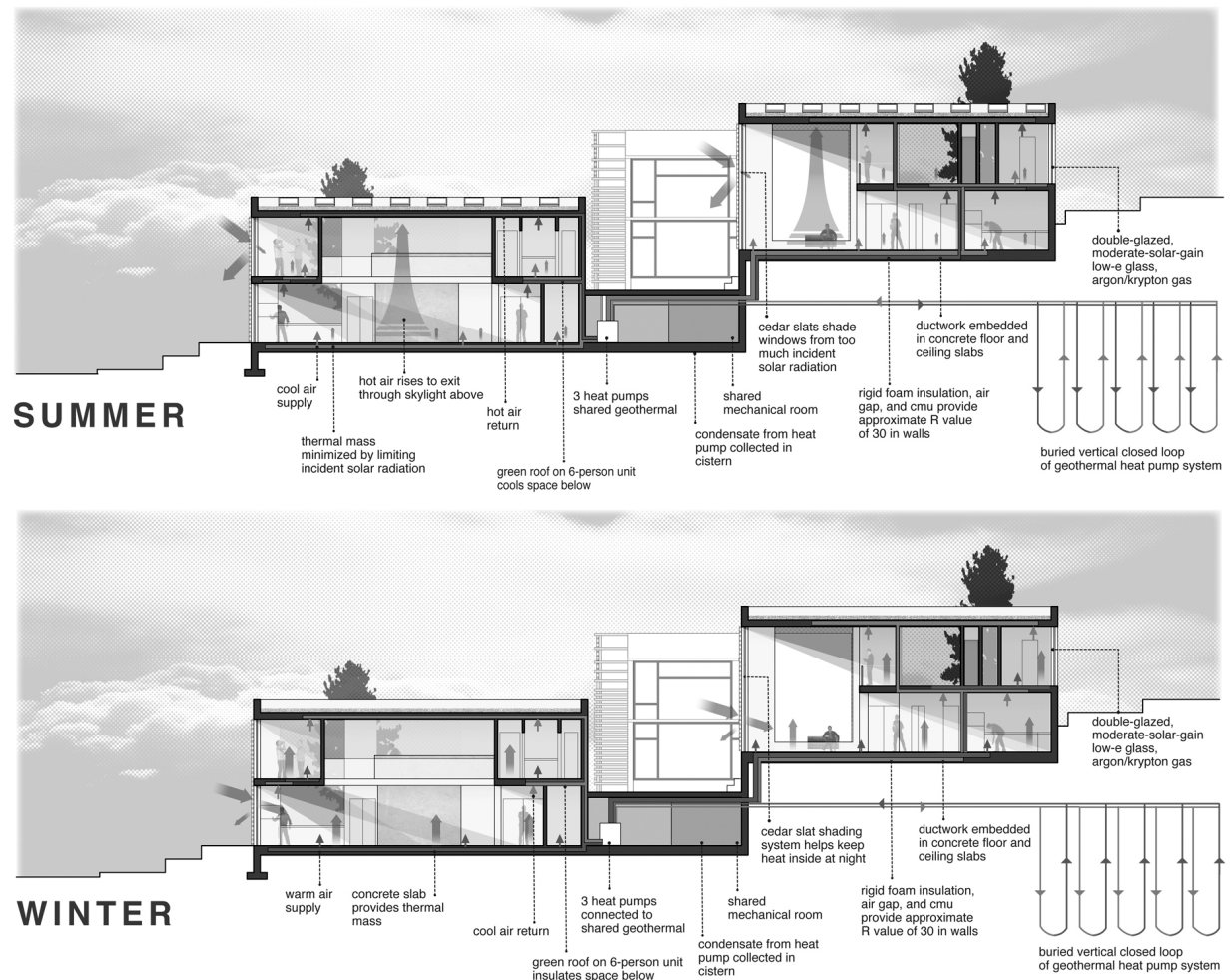

Fig. 6 Design to zero competition, heating and cooling concept [1]. 

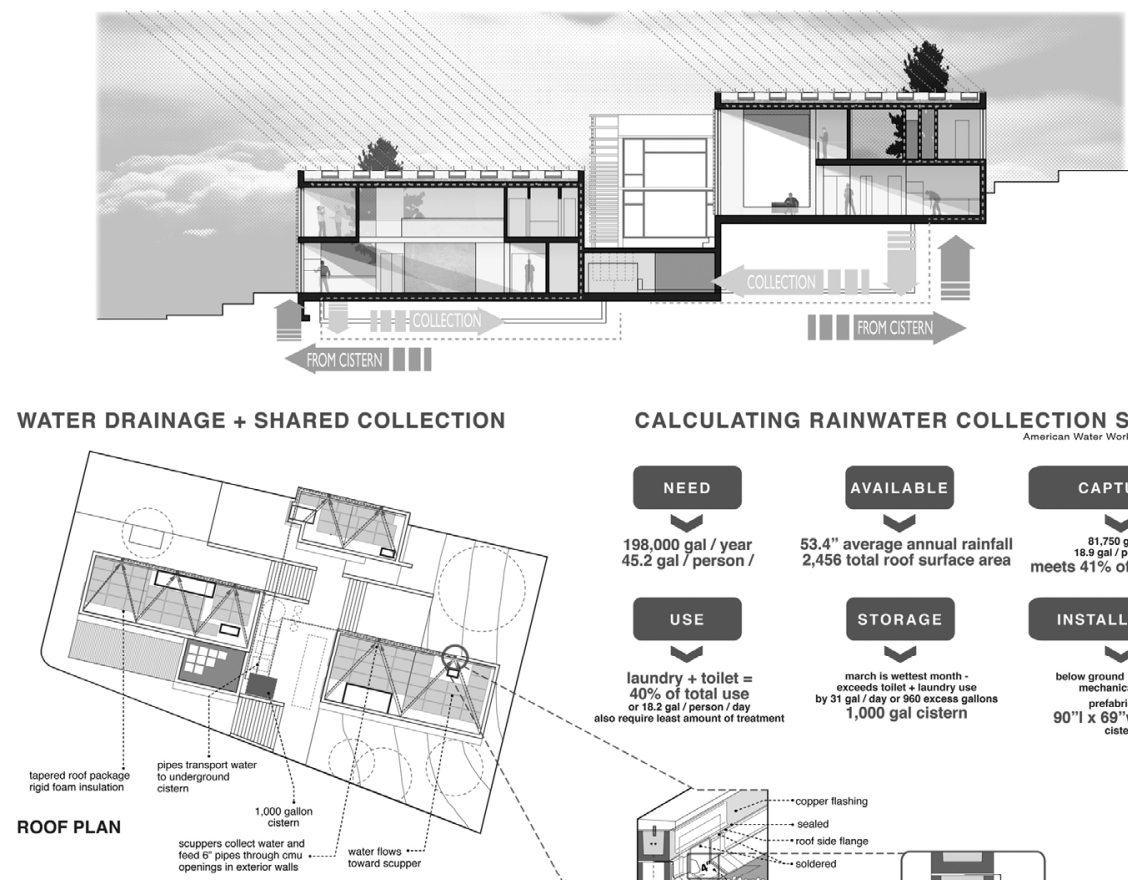

CALCULATING RAINWATER COLLECTION SYSTEM
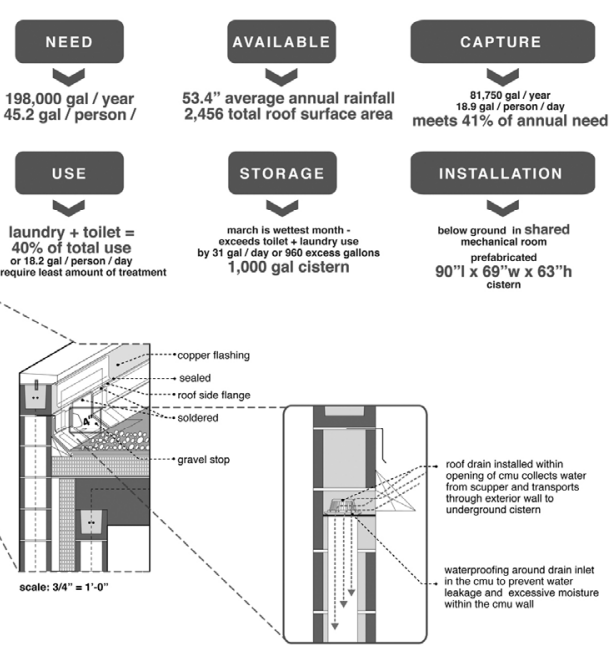

Fig. 7 Design to zero competition, rainwater collection [1].

powered $100 \%$ with energy harvested through the photovoltaic system.

\subsection{Geothermal/Ground Heat Pump}

The ground heat pump is a central heating or cooling system that pumps heat through or from the ground. It uses the earth as a heat source in the winter or a heat sink in the summer. Depending on their sites, students were challenged to decide on an open versus a closed loop or a horizontal versus a vertical loop and air or water delivery. The site had to be analyzed in terms of its annual average ground temperature and its size for the placement of the system [5].

The optimal way to save embedded energy and money is to make buildings last longer. Through passive heating and cooling systems, day lighting, and natural ventilation, energy needs are low (Fig. 6).

\subsection{Rain Water Harvesting}

Rainwater catchment systems collect and store rainwater for reuse for potable uses, irrigation, laundry and passive cooling [5].

Rainwater is collected and provides a large percentage of the units' water needs. A solar thermal hot water system uses solar radiation to heat the water.

Rainwater harvesting systems, which can be simply constructed from inexpensive local materials, are potentially successful in most habitable locations. The students in the studio were challenged to coordinate their sites, roof planes and materials and define a storage location. Calculations determining the amount of water harvested throughout the year were requested (Fig. 7).

\section{Conclusions}

It is the author's strong belief that teaching integrated design is the key to sustainable design education. Rather than allowing the design process to be subdivided into concept, design process and technologies, architectural projects should be 
developed holistically and be implemented for specific climatic and urban conditions. Fundamental research of the context is the foundation for a scientifically grounded and, therefore, sustainable project. The students participating in this project responded very positively to the content of the studio and their new design tools, which were incorporated in their subsequent projects, continuing their reconsideration and evaluation of their existing design tools, living patterns and values.

Their overwhelming success in the international competition, which included 131 submissions from 19 countries, earning 5 of the 11 prizes suggests that this approach is the best one for teaching the next generation of architects. Co-teaching by faculty with different areas of expertise was also a good experience for the students as they prepare to become practicing architects.

\section{References}

[1] C. Ranson, D. Kim, Project Zero, Design to Zero Competition, 2011, http://people.clemson.edu/ dwkim/ DesignToZero/index.html (accessed Jan. 1, 2014).

[2] US Census Bureau, Housing and Household Economic Statistics Division, American Housing Survey National Table, 2007, http://www.census.gov/hhes/www/housing/ ahs/ahs07/tab1a-1.pdf (accessed Jan. 1, 2008).

[3] J. Ruegemer, Teaching Sustainable Strategies in Architecture: Learning from the Global Perspective, Les Presses de 1'Universite Laval, Quebec, Canada, 2009.

[4] H. Koch-Nielsen, Stay Cool—A Design Guide for the Built Environment in Hot Climates, Earthscan, London, 2007.

[5] A. Kwok, W. Grondzik, The Green Studio Handbook-Environmental Strategies for Schematic Design, Elsevier Inc., Burlington, 2011.

[6] M. Hegger, M. Fuchs, T. Stark, M. Zeumer, Energy Manual-Sustainable Architecture, Birkhaeuser Verlag, 2008.

[7] R. Gonzalo, K. Habermann, Energy Efficient Architecture, Birkhaeuser Publisher for Architecture, Boston, Berlin, 2006. 